\title{
Technical Note: Precise quantitative measurements of total dissolved inorganic carbon from small amounts of seawater using a gas chromatographic system
}

\author{
T. Hansen, B. Gardeler, and B. Matthiessen \\ GEOMAR, Helmholtz Center for Ocean Research Kiel, Duesternbrooker Weg 20, 24105 Kiel, Germany \\ Correspondence to: T. Hansen (thansen@geomar.de)
}

Received: 20 February 2013 - Published in Biogeosciences Discuss.: 7 March 2013

Revised: 6 September 2013 - Accepted: 9 September 2013 - Published: 22 October 2013

\begin{abstract}
Total dissolved inorganic carbon $\left(C_{\mathrm{T}}\right)$ is one of the most frequently measured parameters used to calculate the partial pressure of carbon dioxide in seawater. Its determination has become increasingly important because of the rising interest in the biological effects of ocean acidification. Coulometric and infrared detection methods are currently favored in order to precisely quantify $C_{\mathrm{T}}$. These methods however are not sufficiently validated for $C_{\mathrm{T}}$ measurements of biological experiments manipulating seawater carbonate chemistry with an extended $C_{\mathrm{T}}$ measurement range $(\sim 1250$ $2400 \mu \mathrm{mol} \mathrm{kg}^{-1}$ ) compared to natural open ocean seawater $\left(\sim 1950-2200 \mu \mathrm{mol} \mathrm{kg}{ }^{-1}\right)$. The requirement of total sample amounts between $0.1-1 \mathrm{~L}$ seawater in the coulometric- and infrared detection methods potentially exclude their use for experiments working with much smaller volumes. Additionally, precise $C_{\mathrm{T}}$ analytics become difficult with high amounts of biomass (e.g., phytoplankton cultures) or even impossible in the presence of planktonic calcifiers without sample pre-filtration. Filtration however, can alter $C_{\mathrm{T}}$ concentration through gas exchange induced by high pressure. Addressing these problems, we present precise quantification of $C_{\mathrm{T}}$ using a small, basic and inexpensive gas chromatograph as a $C_{\mathrm{T}}$ analyzer. Our technique is able to provide a repeatability of $\pm 3.1 \mu \mathrm{mol} \mathrm{kg}{ }^{-1}$, given by the pooled standard deviation over a $C_{\mathrm{T}}$ range typically applied in acidification experiments. $200 \mu \mathrm{L}$ of sample is required to perform the actual $C_{\mathrm{T}}$ measurement. The total sample amount needed is $12 \mathrm{~mL}$. Moreover, we show that sample filtration is applicable with only minor alteration of the $C_{\mathrm{T}}$. The method is simple, reliable and with low cumulative material costs. Hence,
\end{abstract}

it is potentially attractive for all researchers experimentally manipulating the seawater carbonate system.

\section{Introduction}

Oceanic absorption of anthropogenic carbon dioxide $\left(\mathrm{CO}_{2}\right)$ in the past and during the next decades leads to seawater acidification (Caldeira and Wickett, 2003), which will increasingly influence biological and biochemical processes in the open oceans (Doney et al., 2009; Houghton, 1995; Kroeker et al., 2010) and in coastal waters (Melzner et al., 2012). Due to this fact, scientific interest in precise measurements of $C_{\mathrm{T}}$ has increased. Among other parameters, such as total alkalinity and $\mathrm{pH}, C_{\mathrm{T}}$ is used to describe the seawater carbonate system. The measurement range for $C_{\mathrm{T}}$ in experimental studies $\left(\sim 1250-2400 \mu \mathrm{mol} \mathrm{kg}^{-1}\right)$ ( e.g., Thomsen et al., 2013; Yu et al., 2011; Melzner et al., 2011; and Lohbeck et al., 2012) usually exceeds the typically applied measurement range of $C_{\mathrm{T}}$ in open ocean water $\left(\sim 1950-2200 \mu \mathrm{mol} \mathrm{kg}{ }^{-1}\right)$. Often only small sample volumes are available. Moreover, such experiments often contain non-negligible quantities of biomass (e.g., from phytoplankton cultures), which require sample filtration (Mueller et al., 2012; Matthiessen et al., 2012) before precise $C_{\mathrm{T}}$ measurement can be performed.

Several analytical methods have been established to quantify the $C_{\mathrm{T}}$ content in water samples. The commonly applied techniques (i.e., coulometric and infrared detection method) convert $C_{\mathrm{T}}$ into $\mathrm{CO}_{2}$ by acid addition prior to quantification by a highly precise gas-detection system (Johnson et al., 1985; Wong, 1970). Today the coulometric $C_{\mathrm{T}}$ 
Table 1. Comparison of established $C_{\mathrm{T}}$ measurement methods. Specific measures of precision from the literature are summarized as repeatability.

\begin{tabular}{lllll}
\hline Method & Injected volume & $\begin{array}{l}\text { Collected sample } \\
\text { volume }\end{array}$ & $\begin{array}{l}\text { Total sample } \\
\text { volume } \\
\text { required after } \\
\text { SOP 1 }\end{array}$ & Repeatability \\
& & \multicolumn{4}{c}{} & & \\
\hline Coulometric & $\sim 30 \mathrm{~mL}$ & $150-500 \mathrm{~mL}$ & $>300 \mathrm{~mL}$ & $\pm 1.5 \mu \mathrm{mol} \mathrm{kg}^{-1 \mathrm{a}}$ \\
NDIR & $2.5-10 \mathrm{~mL}$ & $50-250 \mathrm{~mL}$ & $>100 \mathrm{~mL}$ & $\pm 2 \mu \mathrm{mol} \mathrm{kg}^{-1 \mathrm{~b}}$ \\
Photometric & $\sim 0.5 \mathrm{~mL}$ & $\sim 50 \mathrm{~mL}$ & $\sim 100 \mathrm{~mL}$ & $\pm 3 \mu \mathrm{mol} \mathrm{kg}^{-1 \mathrm{c}}$ \\
"Old GC" & $\sim 2 \mathrm{~mL}$ & $\sim 150 \mathrm{~mL}$ & $\sim 300 \mathrm{~mL}$ & $\pm 7 \mu \mathrm{mol} \mathrm{kg}^{-1 \mathrm{~d}}$ \\
\hline
\end{tabular}

a Johnson et al. (1993); ${ }^{\mathrm{b}}$ Goyet and Snover (1993); ${ }^{\mathrm{c}}$ Stoll et al. (2001); ${ }^{\mathrm{d}}$ Weiss and Craig (1973).

analysis is the most preferred method in oceanographic research with the highest precision of $\pm 0.06 \%$, which equals $\pm 1.5 \mu \mathrm{mol} \mathrm{kg} \mathrm{kg}^{-1}$ (Table 1) for a typical open ocean water measurement range (see above) (Johnson et al., 1993). This precision is needed because present ocean acidification causes only a small increase of $\sim 1 \mu \mathrm{mol} \mathrm{kg} \mathrm{yr}^{-1}$, which is added to a $C_{\mathrm{T}}$ background of $\sim 2100 \mu \mathrm{mol} \mathrm{kg} \mathrm{kg}^{-1}$ (Houghton, 1995). Disadvantages of this semi-automatic method are the necessity of relatively large total sample volumes $(\sim 0.3-$ $1 \mathrm{~L})$ and the requirement of highly toxic chemicals such as ethanolamine and hydroxyethylcarbamic acid (Dickson and Goyet, 1994; Johnson et al., 1985). The improved infrared detection method (non-dispersive infrared analysis, NDIR) (Kaltin et al., 2005) and a newer photometric method (continuous-flow analysis) (Stoll et al., 2001) for $C_{\mathrm{T}}$ measurements corrected for these drawbacks by a faster sample throughput, using less toxic chemicals and requiring only a small amount of sample. However, these new methods decreased the measurement precision by $\pm 0.08 \%$ (Table 1 ).

Gas chromatography (GC) analysis of the $C_{\mathrm{T}}$ content from sea water samples was first tested in the early 1960s (Park and Catalfomo, 1964; Swinnerton et al., 1962), and improved for precision in the beginning of the 1970s (Weiss and Craig, 1973). The GC measurement process was divided into three temperature controlled parts. First, sample and acid addition into the stripping chamber was performed at ambient temperature. Second, released gases from the chamber were transferred by the carrier gas into the GC components at $40^{\circ} \mathrm{C}$. A sub-sample was collected using a $0.1 \mathrm{~mL}$ sample loop. Third, $\mathrm{CO}_{2}$ was separated by a silica gel column at $45^{\circ} \mathrm{C}$ and finally quantified by a thermal conductivity detector. Approximately 0.3-1 L of total sample volume was required for sampling, rinsing the analytical system and finally measuring a sample. The precision of the GC method was denoted with a $0.7-$ $0.3 \%$ relative standard deviation for the open ocean $C_{\mathrm{T}}$ range (Swinnerton et al., 1962; Weiss and Craig, 1973). However, this kind of GC method (hereafter referred to as "old GC method") has not been established as a common technique to quantify $C_{\mathrm{T}}$.
In contrast, for non-quantitative stable isotope analysis of dissolved inorganic carbon $\left(\delta^{13} \mathrm{C}\right.$; DIC) GC has become a standard method applying a head space technique (Capasso et al., 2005; Salata et al., 2000; St-Jean, 2003). For this purpose sealed vials containing $<20 \mathrm{~mL}$ of sample were acidified. After $\mathrm{CO}_{2}$ equilibration $(\sim 24 \mathrm{~h})$ between water and the head space a gas sub-sample was collected from the latter. The $\mathrm{CO}_{2}$ was separated by a GC column and transferred to a stable isotope ratio mass spectrometer via an interface. $\delta^{13} \mathrm{C}$ values for DIC measurements were determined with a good precision of $\pm 0.1 \%$ (Salata et al., 2000). However, this quantification of DIC has never been validated against a certified reference material (Dickson, 2010).

Here we present a gas chromatographic technique precisely quantifying $C_{\mathrm{T}}$ of measurement ranges typically emerging in experimentally manipulated acidification studies. A $C_{\mathrm{T}}$ measurement is performed by sample injection of only $200 \mu \mathrm{L}$ taken from a $10 \mathrm{~mL}$ sample. $2 \mathrm{~mL}$ samples are required for rinsing the sampling tube. That is, a total sample volume of $12 \mathrm{~mL}$ for each sample. Moreover, we show that sample filtration leads only to minimal alterations of the $C_{\mathrm{T}}$.

Our method was verified by certified reference material (Dickson, 2010) and tested using samples comprising high biomass of calcifying phytoplankton in low and high $C_{\mathrm{T}}$ concentrations.

\section{Material and procedures}

\subsection{Instrumental setup}

The analytical system consisted of a small gas chromatograph $(8610 \mathrm{C} ; 48 \mathrm{~cm} \times 34 \mathrm{~cm} \times 37 \mathrm{~cm} ; \quad$ SRI-Instruments, California, USA), a $C_{\mathrm{T}}$ measurement chamber $(10 \mathrm{~mL}$ headspace crimp vial; $23 \mathrm{~mm} \times 48 \mathrm{~mm}$; sealed with a butyl rubber septum; Restek, Bad Homburg, Germany), and an external automated cooling trap (Thermo Fisher Scientific, Bremen, Germany) (Fig. 1a, b). Transfer lines between the $C_{\mathrm{T}}$ measurement chamber, gas chromatograph, and cooling trap were made from fused silica (Guard column, $0.53 \mathrm{~mm}$ ID; Restek, Bad Homburg, Germany). In order to penetrate 


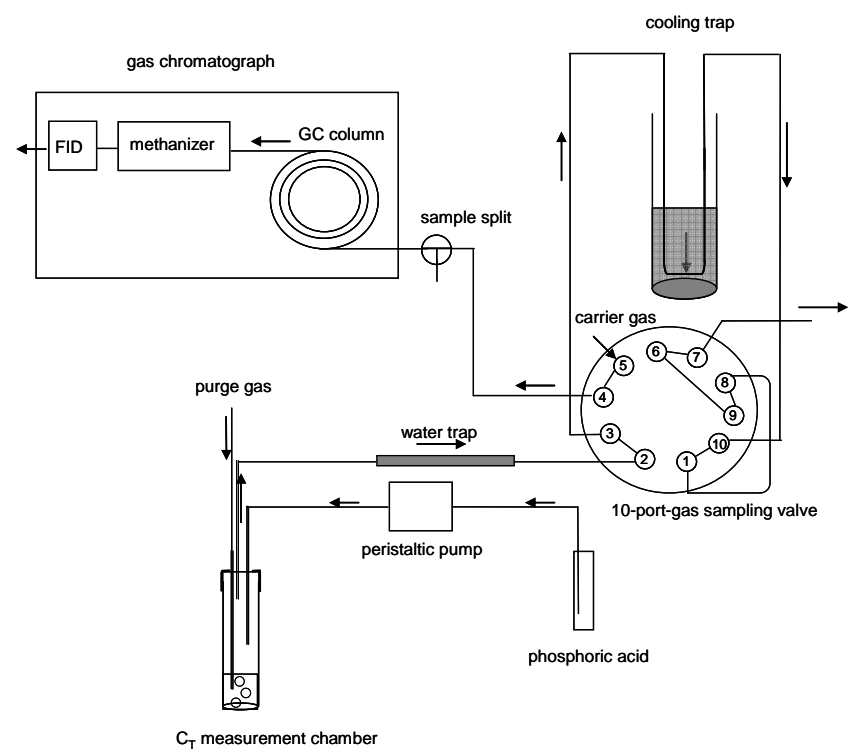

Fig. 1a. $C_{\mathrm{T}}$ analyzer setup in "sample load position" collecting released $\mathrm{CO}_{2}$ from a sample.

the septum of the measurement chamber, stainless steal injection needles $(0.80 \times 80 \mathrm{~mm}$; Unimed, Lausanne, Switzerland) were used. The gas chromatograph was equipped with a 10-port-gas sampling valve, a methanizer (nickel catalyst, $380^{\circ} \mathrm{C}$; SRI-Instruments, California, USA) and a flame ionization detector (FID) (SRI-Instruments, California, USA) (Fig. 1a, b). The catalytic efficiency was stable during all measurements. Phosphoric acid addition into the $\mathrm{C}_{T}$ measurement chamber to convert $C_{\mathrm{T}}$ into $\mathrm{CO}_{2}$ was conducted by a peristaltic pump (IPC; Ismatec, Glattbrugg, Switzerland). $\mathrm{CO}_{2}$ separation was performed by a micro packed GC column for permanent gases (Shincarbon ${ }^{\circledR}$, $120 \mathrm{~mm}$ length, $1 \mathrm{~mm}$ inner diameter (ID); Restek, Bad Homburg, Germany) using the following temperature program: initial $45^{\circ} \mathrm{C}$ held for 9.8 minutes (min), ramp $50{ }^{\circ} \mathrm{C} \mathrm{min}^{-1}$ to $180^{\circ} \mathrm{C}$ and held for $2 \mathrm{~min}$. Moisture was removed by a water trap. The trap consisted of a glass tube (length $\sim 20 \mathrm{~cm}$, outer diameter $6 \mathrm{~mm}$ ) that was filled with phosphorus pentoxide $\left(\mathrm{P}_{2} \mathrm{O}_{5}\right)$ (SICAPENT ${ }^{\circledR}$ with indicator; Merck, Darmstadt, Germany). All connections were sealed by Swagelok reducing connectors of $1 / 8$ to $1 / 16$ in. (water trap connection) and straight connectors of $1 / 16$ in. (Guard column connection) using graphite-vespel ferrules $(1 / 8$ in. to $6 \mathrm{~mm} \mathrm{ID}$, or $1 / 16$ in. to $0.53 \mathrm{~mm}$ ID; Restek, Bad Homburg, Germany). Helium (purity $99.9996 \%$ ) used as carrier gas was set to $\sim 30 \mathrm{~mL} \mathrm{~min}^{-1}$ with a column split flow ratio of 2.5 . The helium purge flow was adjusted to $50 \mathrm{~mL} \mathrm{~min}^{-1}$. Data processing, action of the 10-port-gas sampling valve, and activation of the cooling trap (SRI Instruments Europe GmbH, Bad Honnef, Germany) was operated by the GC software "Peak simple" (version 2.83; SRI-Instruments, California, USA).

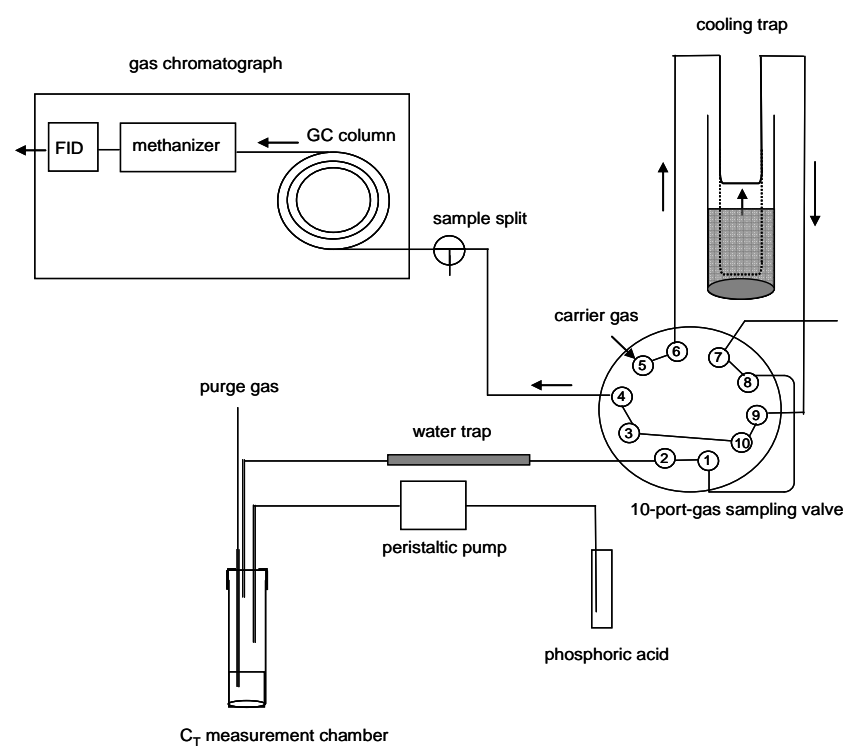

Fig. 1b. $C_{\mathrm{T}}$ analyzer setup in "sample injection position", $\mathrm{CO}_{2}$ released from trap is loaded into the column for analysis.

\subsection{Preparation of $C_{\mathrm{T}}$ measurement chambers}

In order to prepare chambers for $C_{\mathrm{T}}$ measurements $10 \mathrm{~mL}$ glass vials and septa as described above were used. Prior to sealing, each vial was equipped with a small magnetic stir bar $(10 \mathrm{~mm} \times 6 \mathrm{~mm})$. Subsequent additions and connections into and out of the vial were made by injection needles penetrating the sealing (see instrumental setup above). In the next step vials were pre-purged with nitrogen at a flow rate of $\sim 30 \mathrm{~mL} \mathrm{~min}^{-1}$ for $20 \mathrm{~s}$. Thereafter, $1 \mathrm{~mL}$ of deionized water (DI water) was added into each vial. These prepared vials, now defined as the $C_{\mathrm{T}}$ measurement chambers, were integrated into the analytical system by connection to the helium purge supply and a transfer line directing to the cooling trap (Fig. 1a, b).

In the following the same type of vials and sealing were used for sample collections and for preparation of $C_{\mathrm{T}}$ reference standards.

\subsection{Preparation of a sodium carbonate solution used a s $C_{\mathrm{T}}$ lab standard}

The $C_{\mathrm{T}}$ lab standard consisted of highly pure sodium carbonate (Suprapur ${ }^{\circledR}, 99.999 \%$; Merck, Darmstadt, Germany) and DI water. A defined amount of $\sim 3 \mathrm{mg}$ anhydrous sodium carbonate (SOP 2, Annexe B; Dickson and Goyet, 1994) was weighed into a small tin capsule $(5 \times 9 \mathrm{~mm}$ Hekatech, Wegberg, Germany) using a micro balance ( $\mathrm{SC} 2$, readability: $0.1 \mu \mathrm{g}$; Sartorius, Göttingen, Germany), and subsequently transferred into a pre-weighed $10 \mathrm{~mL}$ vial. The vial was carefully filled up to the maximum with DI water using the same peristaltic pump described in the instrumental setup above. The occurrence of turbulences and air bubbles was avoided. 


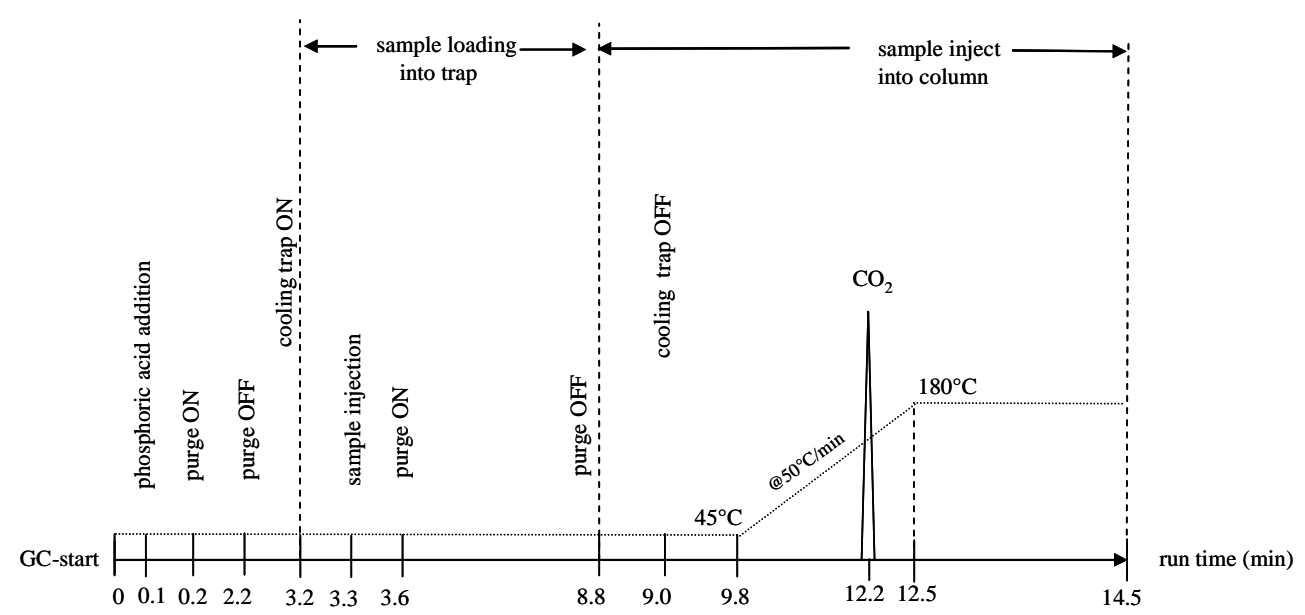

Fig. 2. Operating sequence of the GC- $C_{\mathrm{T}}$ measurement for one sample.

Afterwards the vial was sealed and weighed once again. The headspace was kept below $1 \%$. Finally, the exact $C_{\mathrm{T}}$ concentration was calculated.

\subsection{Preparation of sub-samples and filtered sub-samples from certified reference material (CRM)}

Sub-samples (sub-CRM) of certified reference material CRM (batch 108, $C_{\mathrm{T}}=2022.7 \pm 0.45 \mu \mathrm{mol} \mathrm{kg}^{-1}$ ) (Dickson, 2010) were carefully drawn from an original bottle containing $500 \mathrm{~mL}$ using a Tygon ${ }^{\circledR}$ plastic tube $(1.65 \mathrm{~mm}$ ID). The sub-samples were forced into $10 \mathrm{~mL}$ vials by gravity. In order to initiate the flow, a $10 \mathrm{~mL}$ single-use syringe was used to draw the sample into the tube. Samples were immediately sealed to avoid gas diffusion. Approximately 20 sub-samples were prepared.

Filtered sub-samples (filtered sub-CRM) were taken with the peristaltic pump (see instrumental setup above) into $10 \mathrm{~mL}$ vials. The filtration was conducted using a single-use syringe filter $(0.2 \mu \mathrm{m}$; Minisart RC25, Sartorius, Göttingen, Germany) which was connected to the intake tube (Tygon ${ }^{\circledR}$ plastic tube, $1.65 \mathrm{~mm}$ ID) of the pump. The flow rate was set to $\sim 6 \mathrm{~mL} \mathrm{~min}^{-1}$ in order to avoid turbulence and degassing during the filling process. Vials were immediately sealed after filling.

\section{5 $C_{\mathrm{T}}$ sampling procedure from calcifying phytoplankton cultures}

Test samples from cultures containing the planktonic calcifier Emiliania huxleyi were collected into $10 \mathrm{~mL}$ vials. In order to obtain samples with different $C_{\mathrm{T}}$ (i.e., low, medium, and high), samples were taken from three different cultures with non-manipulated (low) and enriched (medium and high) $C_{\mathrm{T}}$ respectively. $C_{\mathrm{T}}$ enrichment of the culture media was achieved by bubbling with an air- $\mathrm{CO}_{2}$ mixture. In order to remove biomass from the samples filtration was conducted as described above. The filtered samples were poisoned with $2 \mu \mathrm{L}$ saturated $\mathrm{HgCl}_{2}$ solution, and immediately sealed and stored at $4{ }^{\circ} \mathrm{C}$ in darkness until the measurement procedure.

\subsection{GC- $C_{\mathrm{T}}$ measurement procedure and calibration}

Following the time axis in Fig. 2, a $C_{\mathrm{T}}$ measurement was started by the GC program with an addition of $0.8 \mathrm{~mL}$ concentrated phosphoric acid (85\% p.a. (per analysi); Merck, Darmstadt, Germany) into the prepared $C_{\mathrm{T}}$ measurement chamber (Fig. 1a). In the next step the acidified and continuously stirred (magnetic stirrer, RCT basic; Staufen, Germany) DI water inside the chamber was pre-purged with helium for $2 \mathrm{~min}$ in order to reduce background carbon dioxide to a minimum. The purge gas flow was stopped and the cooling trap was activated (Fig. 1a). After $\sim 1$ min the gas pressure inside the $C_{\mathrm{T}}$ measurement chamber was close to ambient pressure. Now a sample injection of $200 \mu \mathrm{L}$ into the $C_{\mathrm{T}}$ measurement chamber was performed manually using a calibrated digital syringe ${ }^{\mathrm{TM}}$ (DS80700; $250 \mu \mathrm{L}$; Hamilton, Nevada, USA). A few seconds later the gas purge flow was started once again and the released $\mathrm{CO}_{2}$, which hereafter passed the $\mathrm{P}_{2} \mathrm{O}_{5}$ (water trap), was collected by the cooling trap (Wong, 1970) with liquid nitrogen (Fig. 1a). The purge flow was stopped after $5.2 \mathrm{~min}$ and the 10-port-gas sampling valve was set to "inject position" (Fig. 1b). After the cooling trap was deactivated, $\mathrm{CO}_{2}$ was removed at ambient temperature and transferred into the column at $45^{\circ} \mathrm{C}$. Rapidly heating the column up to $180^{\circ} \mathrm{C}$ desorbed the $\mathrm{CO}_{2}$. The $\mathrm{CO}_{2}$ passed the catalyst (methanizer) and was converted into methane. Finally, the methane was measured by the FID (Fig. 1b). Time for a complete analysis took $14.5 \mathrm{~min}$ (Fig. 2). $\mathrm{C}_{T}$ was determined from the methane peak area. The $C_{\mathrm{T}}$ analyzer was calibrated daily by measuring certified reference material (CRM; Dickson, 2010). Applying the rule of proportion, $C_{\mathrm{T}}$ values in $\mu \mathrm{mol} \mathrm{kg}^{-1}$ were calculated by the measured 

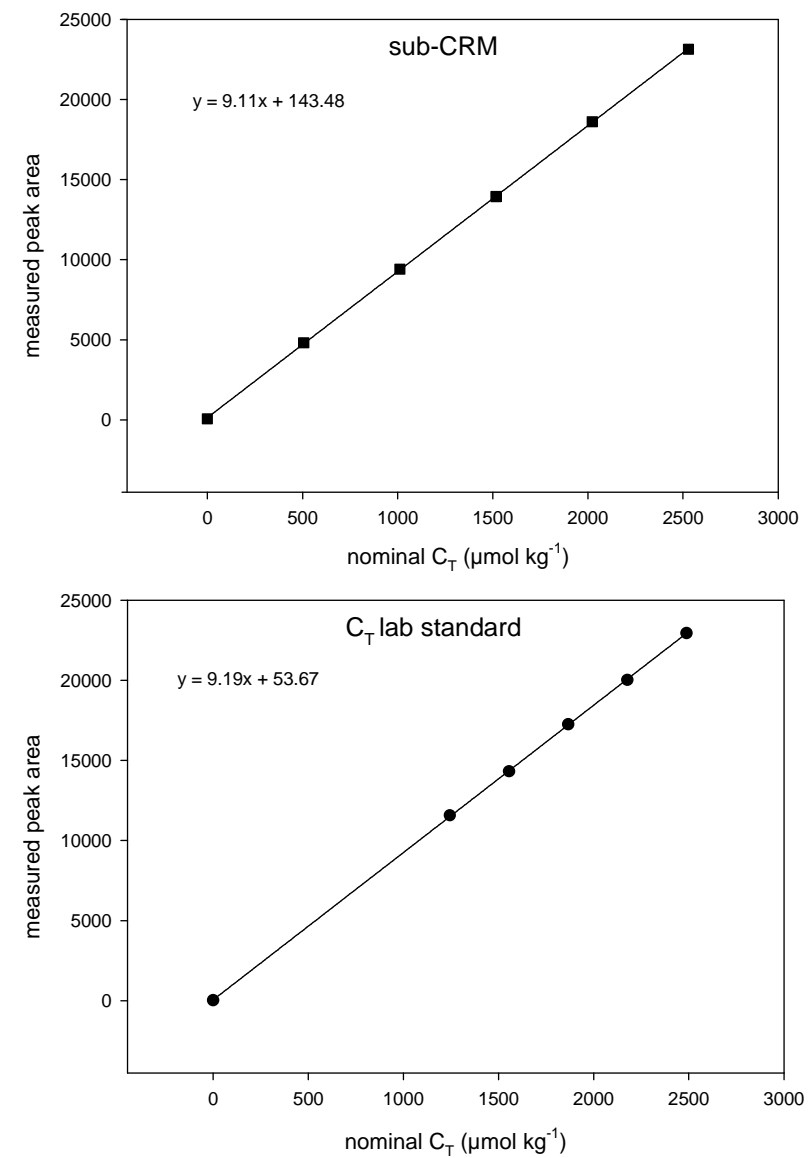

Fig. 3. Measurement linearity indicated by calculated nominal $C_{\mathrm{T}}$ in $\mu \mathrm{mol} \mathrm{kg}{ }^{-1}$ of sub-CRM and $C_{\mathrm{T}}$ lab standard versus measured peak area, respectively.

peak areas of both the actual sample and the measured CRM or sub-CRM.

In order to account for background $\mathrm{CO}_{2}$, the $\mathrm{CO}_{2}$ amount obtained from a pre-purged and acidified $C_{\mathrm{T}}$ measurement chamber without sample injection was used as a blank measurement. Each measurement using the $C_{\mathrm{T}}$ lab standard contained an additional blank by the injection of $200 \mu \mathrm{L}$ DI water, which was used as the solvent to prepare the sodium carbonate solution. Consequently measurements with the $C_{\mathrm{T}}$ lab standard involved were blank corrected.

\subsection{Method validation}

All measurements were conducted under the same conditions adhering to repeatability, i.e., analysis was performed by the same operator in the same laboratory using the same equipment. The laboratory was air-conditioned and set to $20^{\circ} \mathrm{C}$.

In order to show the measurement linearity, we measured the $C_{\mathrm{T}}$ amount by injection of different volumes (range 100$250 \mu \mathrm{L}, 50 \mu \mathrm{L}$ steps) of the sub-CRM and $C_{\mathrm{T}}$ lab standard, respectively (Fig. 3). For the sub-CRM the nominal measurement range was $\sim 500-2500 \mu \mathrm{mol} \mathrm{kg}^{-1}$. For the $C_{\mathrm{T}}$ lab stan- dard a range of nominal $\sim 1250-2500 \mu \mathrm{mol} \mathrm{kg}^{-1}$ was covered. Measured peak areas were plotted against nominal $C_{\mathrm{T}}$ concentrations.

In order to investigate potential effects on measurement quality of $C_{\mathrm{T}}$ by sub-sampling and sample filtration, we conducted $C_{\mathrm{T}}$ measurements taken from CRM $(500 \mathrm{~mL})$, sub-CRM $(10 \mathrm{~mL})$ and filtered sub-CRM $(10 \mathrm{~mL})$. Additionally, as a reality check, natural samples of seawater, which contained calcifying phytoplankton and had different (low, medium and high), $C_{\mathrm{T}}$ were measured. Such samples represent the most difficult analytical conditions because they require filtration prior to $C_{\mathrm{T}}$ measurements. Each sample was measured three times, and mean and standard deviation (SD) were calculated, respectively. In the following the quality (repeatability) of $C_{\mathrm{T}}$ measurements is given by a pooled standard deviation $S_{\mathrm{p}}$ (IUPAC, 2006). $S_{\mathrm{p}}$ is given for each treatment separately and across all $C_{\mathrm{T}}$ measurements.

\section{Results}

The measurement linearity of our GC system could be determined ( $r^{2}=0.9999 ; n=6$ for both sub-CRM and $C_{\mathrm{T}}$ lab standard, respectively) following a linear regression model: $y=a x+b$; with $y$ and $x$ representing measured peak area and nominal $C_{\mathrm{T}}$ in $\mu \mathrm{mol} \mathrm{kg}{ }^{-1}$, respectively. The regression slope (a) of the sub-CRM was 9.11, the peak area (intercept, b) accounted for 143.48. The regression slope of the $C_{\mathrm{T}}$ lab standard was 9.19 , the peak area represented 53.67 (Fig. 3). Slopes of both standards differed $1 \%$ from each other. Whereas the intercept of the $C_{\mathrm{T}}$ lab standard represented a relatively good agreement with obtained blank measurements (see below), the intercept derived from the subCRM was slightly increased. This was potentially due to slightly higher scatter in the measured sub-CRM. The most probable source of error was the imprecision of the digital syringe, which increased with decreasing injection volume (250-100 $\mu \mathrm{L}$, in $50 \mu \mathrm{L}$ steps) while implementing the nominal $C_{\mathrm{T}}$ values. However, linearity was not applied to calibrate the system, and hence to calculate or correct actual $C_{\mathrm{T}}$ values.

Blank measurements obtained from pre-purged and acidified $C_{\mathrm{T}}$ measurement chambers without sample addition during analysis resulted in $5 \mu \mathrm{mol} \mathrm{kg}{ }^{-1} \pm 1.8$ for all conducted measurements. $\mathrm{C}_{T}$ blank measurements conducted by the injection of only $200 \mu \mathrm{L}$ DI water were slightly higher with $\sim 7 \mu \mathrm{mol} \mathrm{kg}{ }^{-1}$.

Average measurements of sub-CRM and filtered sub-CRM were 2022.1 and $2024.3 \mu \mathrm{mol} \mathrm{kg}^{-1}$, respectively (Table 2). The $S_{\mathrm{p}}$ of $C_{\mathrm{T}}$ measurements of both treatments were \pm 2.8 and $\pm 4.1 \mu \mathrm{mol} \mathrm{kg}{ }^{-1}$, respectively (Table 2 ).

Results for test measurements conducted from filtered samples derived from phytoplankton cultures with low, medium and high $C_{\mathrm{T}}$ showed a $S_{\mathrm{p}}$ of $\pm 1.8, \pm 5.5$, and 
Table 2. Comparison of the CRM with sub-sampled (sub-CRM), and filtered sub-CRM, respectively. Triplicate measurements are given as means \pm standard deviations. $S_{\mathrm{P}}$ refers to pooled standard deviations per treatment.

\begin{tabular}{lll}
\hline & $\left(\right.$ CRM, $500 \mathrm{~mL}$, batch $\left.108, C_{\mathrm{T}}=2022.7 \pm 0.45 \mu \mathrm{mol} \mathrm{kg}^{-1}\right)$ \\
\hline \multicolumn{2}{c}{ Measured peak area of CRM $\pm 2.2 \mu \mathrm{mol} \mathrm{kg}{ }^{-1}$} \\
\hline Sample & Sub-CRM $\left(\mu \mathrm{mol} \mathrm{kg}{ }^{-1}\right)$ & Filtered sub-CRM $\left(\mu \mathrm{mol} \mathrm{kg}^{-1}\right)$ \\
1 & $2020.9 \pm 3.6$ & $2028.2 \pm 4.2$ \\
2 & $2022.3 \pm 1.5$ & $2020.5 \pm 5.5$ \\
3 & $2018.0 \pm 1.9$ & $2029.3 \pm 3.7$ \\
4 & $2027.0 \pm 3.6$ & $2019.0 \pm 2.6$ \\
\hline Mean $\pm S_{\mathrm{P}}$ & $2022.1 \pm 2.8$ & $2024.3 \pm 4.1$ \\
\hline
\end{tabular}

Table 3. Comparison of measurements from low, medium and high $C_{\mathrm{T}}$ samples. Samples were derived from calcifying phytoplankton cultures (Emiliania huxleyi), and thus filtered prior to measurements. Triplicate measurements are given as means and standard deviations. $S_{\mathrm{P}}$ refers to pooled standard deviations per treatment.

\begin{tabular}{llll}
\hline Sample & Low $C_{\mathrm{T}}$ & Medium $C_{\mathrm{T}}$ & High $C_{\mathrm{T}}$ \\
\hline 1 & $1846.2 \pm 2.6$ & $2285.0 \pm 4.5$ & $2406.6 \pm 1.0$ \\
2 & $1847.7 \pm 1.6$ & $2289.5 \pm 5.8$ & $2411.1 \pm 2.6$ \\
3 & $1843.0 \pm 0.6$ & $2281.7 \pm 6.2$ & $2415.3 \pm 2.6$ \\
\hline Mean $\pm S_{\mathrm{P}}$ & $1845.6 \pm 1.8$ & $2285.5 \pm 5.5$ & $2411.0 \pm 2.2$ \\
\hline
\end{tabular}

$\pm 2.2 \mu \mathrm{mol} \mathrm{kg}{ }^{-1}$, respectively. The $\mathrm{S}_{p}$ across all samples was $\pm 3.1 \mu \mathrm{mol} \mathrm{kg}{ }^{-1}$.

\section{Discussion}

The here presented $C_{\mathrm{T}}$ quantification method using a GC system allowed for precise measurements with a sample volume of $10 \mathrm{~mL}$ (total required volume $12 \mathrm{~mL}$ ) comprising a typical extended $C_{\mathrm{T}}$ measurement range (1250-2400 $\mu \mathrm{mol} \mathrm{kg}^{-1}$ ) used in biological experiments manipulating seawater carbonate chemistry. $C_{\mathrm{T}}$ measurements were only marginally affected by sample filtration.

Regarding the extended measurement range, the coulometric and NDIR techniques (Goyet and Snover, 1993; Goyet and Hacker, 1992) have solely been validated for the measurement linearity $\left(0-2500 \mu \mathrm{mol} \mathrm{kg}{ }^{-1}\right)$ using an artificial standard (sodium carbonate solution), but not for actual $C_{\mathrm{T}}$ sample measurements. Measurements for an extended $C_{\mathrm{T}}$ measurement range were neither verified by the "old GC" nor by the photometric method (Stoll et al., 2001; Weiss and Craig, 1973).

Additional difficulties in handling $C_{\mathrm{T}}$ samples arise under experimental conditions when calcified phytoplankton biomass requires sample filtration prior to measurements. The relatively good agreement of filtered samples with CRM and sub-CRM and the small $S_{\mathrm{p}}$ underline the reliability of the present analytical method as well as the applicability of sample filtration. However, differences in the average $C_{\mathrm{T}}$ values among filtered and unfiltered CRM and the slightly higher $S_{\mathrm{p}}$ in the filtered set of samples point to the fact that careless handling and filtration of such small volumes prior to measurements are prone to cause imprecision. The $S_{\mathrm{p}}$ of $\pm 5.5 \mu \mathrm{mol} \mathrm{kg}{ }^{-1}$ derived from filtered phytoplankton samples with medium $C_{\mathrm{T}}$ shows that the combination of high phytoplankton biomass, here especially calcifying phytoplankton, and increased $C_{\mathrm{T}}$ represents the most difficult analytical challenge.

Another critical point when measuring $C_{\mathrm{T}}$ from experimentally derived seawater samples is the typically small total sample amount. The requirement of small samples is particularly important when conducting microcosm experiments from which only a few $\mathrm{mL}$ are available for analysis. Whereas the coulometric method requires total sample volumes of $>0.3 \mathrm{~L}$, the NDIR and photometric method need considerably smaller amounts (Table 1). However, while commercial manufacturers of $C_{\mathrm{T}}$ analyzers with NDIR technique (Marianda, Kiel, Germany; Apollo SciTech Inc., Bogart, USA) report about the requirement of a $\sim 10 \mathrm{~mL}$ sample to perform a $C_{\mathrm{T}}$ measurement, no detailed statements are given about (i) the total sample volume required during a sample collection (e.g., SOP 1, Dickson and Goyet, 1994) supplying this technique, and (ii) the volume necessary for the rinsing procedure between alternating high and low $C_{\mathrm{T}}$ measurements. Finally, no verified repeatability or precision is given for processing such samples. Hitherto, due to small sample sizes in this experimental scientific field, the photometric method (Stoll et al., 2001) was preferred.

The GC technique presented in this paper is not comparable with the "old GC method" described by Weiss and Craig (1973), because the new method applies a complete sample transfer instead of a gas sub-sample. Therefore, the complex analytical "old GC system", equipped with a gas sample loop for sub-sampling, is highly sensitive to carrier gas pressure conditions, which in turn requires a constant working temperature during $C_{\mathrm{T}}$ analysis (e.g., $40^{\circ} \mathrm{C}$; Weiss and Craig, 1973). Moreover, the non-separation of purge and 
carrier gas lines tends to cause analytical imprecision by an increased exhaustion of the water trap and the slow accumulation of water in the separation column material. This reduces the gas flow and the separation efficiency during analysis. To get rid of the accumulated water a periodical heating of the separation column of up to $270^{\circ} \mathrm{C}$ for about $4 \mathrm{~h}$ is necessary (Weiss and Craig, 1973).

A potential source of error of the photometric method might be that stored samples have to be opened before analyses (Stoll et al., 2001), which potentially causes $\mathrm{CO}_{2}$ outgassing. This could be particularly critical when using extremely high $C_{\mathrm{T}}$ ranges, e.g., due to manipulated seawater. The other extreme would be particularly low $C_{\mathrm{T}}$ values due to inorganic carbon consumption through phototrophic growth, which potentially leads to gas diffusion into the sample. Opening of the samples is probably necessary due to the robustness of the used sealing, which does not allow for penetration with injection needles when using a common autosampler. Moreover, the photometric method configured as a continuous flow system is sensitive to temperature fluctuations, which causes a baseline drift and thus makes data correction necessary. Signal interferences can occur during analysis in the presence of sulfides, and the dependency on constant ion strength excludes a sample set of different salinities. In comparison, the butyl rubber septa for sample sealing in the present GC system has been proved as gas tight (Brandes, 2009; Spötl, 2004). Manual penetration of this sealing by a syringe in order to collect a sub-sample minimizes the contact to the atmosphere. Chemical interferences and disturbances by different salinities were not observed.

$C_{\mathrm{T}}$ quantification by basic infrared detection is potentially limited because IR measurements are extremely sensitive to water vapor. This requires a strict prevention of water entry into the detector during analysis (Wong, 1970). More sophisticated high precision NDIR detectors (e.g., LI-7000, LICOR-Biosciences, Germany) with water vapor correction overcome this problem; however, they are more expensive. In the GC system presented here, water vapor is not compromising the measurements, because $\mathrm{P}_{2} \mathrm{O}_{5}$ is used as strong water adsorbing material to protect the separation column.

Sample carryover effects were observed in NDIR and coulometric systems, which were equipped with automatic pipettes for sample addition (Kaltin et al., 2005). This effect can occur through insufficient rinsing between subsequent sample measurements and depends on the difference in $C_{\mathrm{T}}$ concentrations among samples. A carryover effect was not reported by authors using the old GC system. However, the usage of a sample loop for transfer into the stripping chamber may show the same problem when using different high $C_{\mathrm{T}}$ concentrations. In general, the quantity of repeated rinsing procedures between such $C_{\mathrm{T}}$ measurements will increase the required sample amount. Our GC method using a $250 \mu \mathrm{L}$ digital syringe was always rinsed twice with the new sample before a new measurement was conducted. Carry over effects were not detected.
The complex manifolds of the NDIR , coulometric and the photometric analyzers as well as the old GC systems consist of a number of tubes, valves and connectors that get contaminated by the highly toxic preservative $\mathrm{HgCl}_{2}$. Handling and operating such systems must be done with care. Handling of the toxic preservative $\mathrm{HgCl}_{2}$ during analysis using the present method could be restricted to the $C_{\mathrm{T}}$ measurement chamber (single-use vials) and sample syringe.

Sample injection with a manual syringe applied in the present $C_{\mathrm{T}}$ quantification method was identified as the most error-prone process during analysis. However, using a digital syringe improved the repeatability of measurement to the here presented $S_{\mathrm{P}}$ of $3.1 \mu \mathrm{mol} \mathrm{kg}{ }^{-1}$. This result still does not meet precision requirements for oceanographic research but will be sufficiently precise for $C_{\mathrm{T}}$ samples derived from manipulated acidification experiments with large measurement ranges with a difference of up to $\sim 1000 \mu \mathrm{mol} \mathrm{kg}^{-1}$. Moreover, the CRM (Dickson, 2010) that was used to calibrate the system had a $\mathrm{pCO}_{2}$ close to ambient values. Thus, due to potential loss of $\mathrm{CO}_{2}$ from high $C_{\mathrm{T}}$ samples and the unavailability of CRM containing high $C_{\mathrm{T}}$, the imprecision for measurements of high $C_{\mathrm{T}}$ samples may be larger and should be subject to more extensive tests.

\section{Conclusions}

It can be concluded that the here presented GC- $C_{\mathrm{T}}$ quantification method offers a number of advantages compared to other methods. In particular the good repeatability of measurement along an extended $C_{\mathrm{T}}$ measurement range, the required very low sample volume and the applicability for sample filtration might lead to establishment of this method as an alternative for $C_{\mathrm{T}}$ quantification of samples from biological ocean acidification experiments.

Acknowledgements. This study was financed by the Leibniz Competitive Fund (SAW-Verfahren im Rahmen des Paktes für Forschung und Innovation 2010). Andrew Dickson and one anonymous reviewer are greatly acknowledged for comments on an earlier version of this manuscript. Ulrich Sommer and Sarah Lena Eggers are greatly acknowledged for cordially commenting on this manuscript prior to submission.

The service charges for this open access publication have been covered by a Research Centre of the Helmholtz Association.

Edited by: J.-P. Gattuso

\section{References}

Brandes, J. A.: Rapid and precise delta C-13 measurement of dissolved inorganic carbon in natural waters using liquid chromatography coupled to an isotope-ratio mass spectrometer, Limnol. Oceanogr.-Methods, 7, 730-739, 2009. 
Caldeira, K. and Wickett, M. E.: Anthropogenic carbon and ocean pH, Nature, 425, 365-365, doi:10.1038/425365a, 2003.

Capasso, G., Favara, R., Grassa, F., Inguaggiato, S., and Longo, M.: On-line technique for preparing and measuring stable carbon isotope of total dissolved inorganic carbon in water samples ( $\delta^{13} \mathrm{C}_{\text {TDIC }}$ ), Ann. Geophys., 48, 159-166, 2005.

Dickson, A. G.: Standards for ocean measurements, Oceanography, 23, 34-47, 2010.

Dickson, A. G. and Goyet, C.: Handbook of methods for the analysis of the various parameters of the carbon dioxide system in sea water, DOE, 1994.

Doney, S. C., Fabry, V. J., Feely, R. A., and Kleypas, J. A.: Ocean Acidification: The Other $\mathrm{CO}_{2}$ Problem, Annu. Rev. Mar. Sci., 1, 169-192, 2009.

Goyet, C. and Hacker, S. D.: Procedure for calibration of a coulometric system used for total inorganic carbon measurements of seawater, Mar. Chem., 38, 37-51, 1992.

Goyet, C. and Snover, A. K.: High-accuracy measurements of total dissolved inorganic carbon in the oceans-comparision of alternate detection methods, Mar. Chem., 44, 235-242, 1993.

Houghton, J. T., Houghton, J. T., Meira Filho, L. G., Callander, B. A., Harris, N., Kattenberg, A., and Maskell, K. (eds.): Climate Change 1995, The Science of Climate Change, J. Atmos. Chem., 27, 105-106, doi:10.1023/a:1005850912627, 1995.

IUPAC: Compendium of Chemical Terminology, 2nd Edn. (the "Gold Book"), compiled by: McNaught, A. D. and Wilkinson, A., Blackwell Scientific Publications, Oxford, 1997.

Johnson, K. M., King, A. E., and Sieburth, J. M.: Coulometric $\mathrm{TCO} 2$ analyses for marine studies; an introduction, Mar. Chem., 16, 61-82, 1985.

Johnson, K. M., Wills, K. D., Butler, D. B., Johnson, W. K., and Wong, C. S.: Coulometric total carbon dioxide analysis for marine studies: maximizing the performance of an automated gas extraction system and coulometric detector, Mar. Chem., 44, 167-187, 1993.

Kaltin, S., Haraldsson, C., and Anderson, L. G.: A rapid method for determination of total dissolved inorganic carbon in seawater with high accuracy and precision, Mar. Chem., 96, 53-60, doi:10.1016/j.marchem.2004.10.005, 2005.

Kroeker, K. J., Kordas, R. L., Crim, R. N., and Singh, G. G.: Meta-analysis reveals negative yet variable effects of ocean acidification on marine organisms, Ecol. Lett., 13, 1419-1434, doi:10.1111/j.1461-0248.2010.01518.x, 2010.

Lohbeck, K. T., Riebesell, U., Collins, S., and Reusch, T. B. H.: Functional genetic divergence in high $\mathrm{CO}_{2}$ adapted Emiliania Huxleyi populations, Evolution, 67, 1892-1900, doi:10.1111/j.1558-5646.2012.01812.x, 2012.

Matthiessen, B., Eggers, S. L., and Krug, S. A.: High nitrate to phosphorus regime attenuates negative effects of rising $p \mathrm{CO}_{2}$ on total population carbon accumulation, Biogeosciences, 9, 1195-1203, doi:10.5194/bg-9-1195-2012, 2012.
Melzner, F., Stange, P., Trübenbach, K., Thomsen, J., Casties, I., Panknin, U., Gorb, S. N., and Gutowska, M. A.: Food Supply and Seawater pCO2 Impact Calcification and Internal Shell Dissolution in the Blue Mussel Mytilus edulis, PLoS ONE, 6, e24223, doi:10.1371/journal.pone.0024223, 2011.

Melzner, F., Thomsen, J., Koeve, W., Oschlies, A., Gutowska, M., Bange, H., Hansen, H., and Körtzinger, A.: Future ocean acidification will be amplified by hypoxia in coastal habitats, Mar. Biol., 1-14, doi:10.1007/s00227-012-1954-1, 2012.

Mueller, M. N., Beaufort, L., Bernard, O., Pedrotti, M. L., Talec, A., and Sciandra, A.: Influence of $\mathrm{CO}_{2}$ and nitrogen limitation on the coccolith volume of Emiliania huxleyi (Haptophyta), Biogeosciences, 9, 4155-4167, doi:10.5194/bg-9-4155-2012, 2012.

Park, K. and Catalfomo, M.: Gas chromatographic determination of dissolved oxygen in sea water using argon as carrier gas, Deep Sea-Res., 11, 917-920, 1964.

Salata, G. G., Roelke, L. A., and Cifuentes, L. A.: A rapid and precise method for measuring stable carbon isotope ratios of dissolved inorganic carbon, Mar. Chem., 69, 153-161, 2000.

Spötl, C.: A simple method of soil gas stable carbon isotope analysis, Rapid Commun. Mass Sp., 18, 1239-1242, doi:10.1002/rcm.1468, 2004.

St-Jean, G.: Automated quantitative and isotopic (13C) analysis of dissolved inorganic carbon and dissolved organic carbon in continuous-flow using a total organic carbon analyser, Rapid Commun. Mass Sp., 17, 419-428, doi:10.1002/rcm.926, 2003.

Stoll, M. H. C., Bakker, K., Nobbe, G. H., and Haese, R. R.: Continuous-Flow Analysis of Dissolved Inorganic Carbon Content in Seawater, Anal. Chem., 73, 4111-4116, doi:10.1021/ac010303r, 2001.

Swinnerton, J. W., Linnenbom, V. J., and Cheek, C. H.: Determination of Dissolved Gases in Aqueous Solutions by Gas Chromatography, Anal. Chem., 34, 483-485, doi:10.1021/ac60184a010, 1962.

Thomsen, J., Casties, I., Pansch, C., Körtzinger, A., and Melzner, F.: Food availability outweighs ocean acidification effects in juvenile Mytilus edulis: laboratory and field experiments, Glob. Change Biol., 19, 1017-1027, doi:10.1111/gcb.12109, 2013.

Weiss, R. F. and Craig, H.: Precise shipboard determination of dissolved nitrogen, oxygen, argon, and total inorganic carbon by gas chromatography, Deep Sea-Res., 20, 291-303, 1973.

Wong, C. S.: Quantitative analysis of total carbon dioxide in sea water: A new extraction method, Deep Sea-Res., 17, 9-17, 1970.

Yu, P. C., Matson, P. G., Martz, T. R., and Hofmann, G. E.: The ocean acidification seascape and its relationship to the performance of calcifying marine invertebrates: Laboratory experiments on the development of urchin larvae framed by environmentally-relevant $p \mathrm{CO}_{2} / \mathrm{pH}$, J. Exp. Mar. Biol. Ecol., 400, 288-295, 2011. 